\title{
ДНИ РОЖДЕНИЯ КАК ИСТОЧНИК ИЗБЫТОЧНОЙ СМЕРТНОСТИ: ДИАГНОСТИЧЕСКИЙ СОСТАВ ПРИЧИН СМЕРТИ
}

\author{
АЛЕКСАНДР НЕМЦОВ, ТИМУР ФАТТАХОВ
}

\begin{abstract}
Постановка проблемы. Ранее было показано, что в России и в мире праздники сопровождаются ростом смертности, главным образом в Рождество и Новый год. А как обстоит дело с диагнозами избыточной смертности при праздновании дней рождений?

Материал и методы. С этой целью исследовали данные 16,77 млн умерших с 01.01.2011 по 31.12.2019 на предмет соотношения дат рождения и смерти. Во всех случаях даты рождения и смерти получили номер дня года. При совпадении этих номеров случаю смерти присваивали значение 0, при несовпадении - число дней различия с днем рождения до или после этого дня от \pm 1 до \pm 182 . Эту прочедуру продельвали как для смертности в целом, так и для 6 больших классов смертей и 8 видов внешних причин. Избыточную смертность в день рождения оченивали с помощью скользящей средней LOWESS (локально взвешенная полиномиальная регрессия), которая описывала смертность в непраздничные дни, а в праздничные дни ее перерывы заполняли линейной регрессией, которая служила показателем «естественной», непраздничной смертности в праздники.
\end{abstract}

Результаты. Выявлен значительный рост смертности в день рождения (4,0 тыс. в день за 9 лет), а всего избыточная смертность, связанная с днем рождения, составила 19,7 тыс. или 3,5\% от «естественной» смертности. Главный вклад в избыточную смертность внесли болезни системы кровообрашения (9,1 тыс.) и внешние причины (5,2 тыс.), а среди внешних причин самоубийства (1,3 тысс.), отравления алкоголем (1,0 тыс.) и повреждения с неопределенными намерениями (0,8 тыс.). Избыточная смертность в день рождения была пропоричональна непраздничной смертности. Исключение составили отравления алкоголем, которые в 2 раза превысили ожидаемое по будням число смертей. Особенность самоубийств состоит в том, что увеличение их количества начинается за 2 месяиа до дня рождения с максимумом за 35 дней, последующим снижением и резким ростом в день рождения. Дальнейшая смертность от самоубийств имеет ичикличность с максимумами на 7-й и 15-й дни после дня рождения. Сравнение с другими праздниками показало, что дни рождения по размерам избыточной смертности занимают промежуточное положение между Новым годом и другими государственными праздниками. Главным фактором избыточной смертности в праздники является злоупотребление крепкими спиртные напитками.

Заключение. День рождения, как и государственные праздники, сопровождается ростом смертности. Легко предположить, что потери этим не исчерпьваются: заболевших в день рождения много больше, чем умерших в связи с этим праздником.

Ключевые слова: день рождения, избыточная смертность, болезни системы кровообращения, внешние причины, отравления алкоголем, самоубийства, убийства.

АЛЕКСАНДР ВИКЕНТЬЕВИЧ НЕМЦОВ (nemtsov33@gmail.com), НАЦИОНАЛЬНЫЙ НАУЧНЫЙ ЦЕНТР НАРКОЛОГИИ МЗ РФ, РОсСия.

ТИМУР АСФАНОВИЧ ФАТТАХОВ (timur300385@mail.ru), НАЦИОНАЛЬНЫЙ ИССЛЕДОВАТЕЛЬСКИЙ УНИВЕРСИТЕТ «ВЫСШАЯ ШКОЛА ЭКОНОМИКИ», РОССИЯ.

В СТАТЬЕ БЫЛИ ЧАСТИЧНО ИСПОЛЬЗОВАНЫ РЕЗУЛЬТАТЫ, ПОЛУЧЕННЫЕ В РАМКАХ ПРОГРАММЫ ФУНДАМЕНТАЛЬНЫХ ИССЛЕДОВАНИЙ НИУ ВШЭ.

СТАТЬЯ ПОСТУПИЛА В РЕДАКЦИЮ В СЕНТЯБРЕ 2021 Г. 


\section{ВВЕДЕНИЕ}

В середине 1970-х впервые был описан «эффект дня рождения» - совпадение роста смертности и месяца рождения (Англия, Уэльс (Anderson 1975: 151)). Позже это подтвердилось на ежедневных данных в Швейцарии (Bovet, Spagnoli, Sudan 1997: 151), в постсоветской Украине (Vaiserman et al. 2003: 221) и в CША (Ajdacic-Gross et al. 2012: 603). Эффект дня рождения (ДР) иногда проявлялся только в мужской популяции (Phillips, Van Voorhees, Todd 1992: 532), но чаще без гендерных различий (Doblhammer 1999: 1; Medenwald, Kuss 2014: e004423.). В США было показано также, что «эффект дня рождения» чаще наблюдается в 20-39 лет (51,0\%), реже до 20 лет (31,3\%), а после 39 лет резко убывает (в 90+ 4,3\%). Совпадение дня рождения и выходного дня увеличивает риск умереть еще больше. Всего в США за 13 лет (1998-2011 гг.) избыточная смертность в день рождения составила 4590 случаев (Реп̃a 2015: 59). Указывалось также, что этот эффект отчасти может быть статистическим артефактом из-за ошибок учета (Abel, Kruger 2009: 175; Phillips, Van Voorhees, Todd 1992: 532). В ряде работ факторами роста смертности в дни рождения назывались злоупотребление алкоголем, напряжение, связанное с днем рождения и самоубийство.

Самоубийству в день рождения посвящено довольно много публикаций, особенно много в Японии. Показан, например, полуторакратный рост числа самоубийств в день рождения (Motohashi 2012: 1282), и начинается он у мужчин за 5 дней до и продолжается неделю после дня рождения с максимумом в день рождения, у женщин этот период шире. При этом период повышенного риска самоубийств зависит от возраста и социального положения умерших (Stickley et al. 2016: 259). А такие вехи в жизни людей, как круглые даты $(20,40,50$ и 60 лет), более чувствительны к суицидальной активности, но особо совершеннолетие и выход на пенсию (Matsubayashi, Lee, Ueda 2019: 16642). Интересно, что в отличие от Великобритании (Williams et al. 2011: 13) в Германии «эффект дня рождения» не обнаружен (Reulbach et al. 2007: 554). В России этот эффект не был исследован, если не считать пилотную работу с участием авторов (Немцов и др. 2021:16).

\section{ЗАДАЧИ ИССЛЕДОВАНИЯ}

Целью данного исследования являлся анализ российских особенностей смертности в дни рождения по диагностическому составу.

\section{МАТЕРИАЛ И МЕТОДЫ}

Данное исследование носит эпидемиологический, ретроспективный, невыборочный характер; последнее дало возможность не прибегать к расчетам статистической значимости. Дизайн исследования позволил обойтись без относительных показателей авторы считают, что абсолютные числа смертей более убедительно показывают размеры потерь. В работе представлен анализ временных рядов ежедневного количества смертей с 1 января 2011 по 31 декабря 2019 г. - всего 16,77 млн умерших (в среднем 1,86 млн в год или 5,1 тыс. в день, от 4,3 до 7,0 тыс.). Были исключены лица без точной даты смерти или 
рождения, а также младенцы в возрасте 0 лет, так как вероятность смертельного исхода для новорожденных наиболее высока в 1-й день жизни. Исключены также дети в возрасте 1 год, у которых присутствует эффект дня рождения, который очевидно не связан с поведенческим фактором. Исключены из анализа умершие 1 января и 1 июля (начало и середина года), так как при паспортизации населения в советский период эти даты часто использовались при неизвестной точной дате рождения человека.

Помимо общего количества смертей исследовали их распределение по основным классам причин смерти в соответствии с МКБ-10: инфекционные и паразитарные заболевания (А00-B99), новообразования (C00-D48), болезни системы кровообращения (I00-I99), болезни органов дыхания (J00-J99), болезни органов пищеварения (K00-К93) и внешние причины (V01-Y98). Кроме того, были проанализированы 8 видов внешних причин смерти: алкогольные отравления (X45+Y15), убийства (X85-Y09), самоубийства (X60-X84), транспортные происшествия (V01-V99), случайные падения (W00-W19), случайное утопление (W65-W74), воздействие огня и пламени (X00-X09) и повреждения с неопределенными намерениями (Y10-Y34).

Случайные отравления алкоголем авторы в соответствии с МКБ-10 рассматривали как сумму причин X45 - случайные отравления алкоголем и Y15 - отравления алкоголем с неопределенными намерениями. Это связано с тем, что в России в последние годы произошло резкое увеличение числа смертей от Y15, что, вероятно, определяется ошибочным кодированием части смертей X45 как смертей Y15. В работе использованы данные об умерших по фактической дате смерти. Смерти без указания точной даты рождения или смерти ${ }^{1}$ были исключены из исследования (54,8 тыс.), как и умершие 29 февраля для удобства расчетов (9,6 тыс.).

Для анализа смертности в связи с днем рождения использовали следующий алгоритм. Дни смерти и рождения каждого умершего были пронумерованы в соответствии с номерами дней в году (от 1 до 365/366). Если номера дня рождения и смерти совпадали, случаю присваивали значение ноль. Если даты рождения и смерти не совпадали, случаю смерти присваивали число дней несовпадения: от 1 до 182, если день смерти следовал за днем рождения в пределах 182 дней, или от -1 до -182 , если день смерти предшествовал дню рождения в пределах $-1 \div-182$. В результате таких расчетов получили распределение, характеризующее частоты смертей в течение года (на шкале \pm 182$)$ вокруг дня рождения, когда дата рождения и смерти совпадали (0 на графиках).

Далее этот ряд дублировали, в нем удаляли день рождения и ближайшие дни повышенной смертности. Во 2-м ряду строили скользящую среднюю LOWESS (LOcally WEighted Scatter-plot Smoother, локально взвешенная полиномиальная регрессия (Cleveland, Devlin 1988: 596); полоса пропускания 0,03), а пропуски автоматически заполняли линейной регрессией, соединяющей концы прерванного LOWESS. Созданную таким образом LOWESS, накладывали на исходный ряд, при этом участок линейной регрессии служил экстраполяцией уровня непраздничной смертности на праздничные дни для измерения избыточной смертности в праздники. Период избыточной смертности

\footnotetext{
${ }^{1}$ Под точной датой понимается дата с известным днем, месяцем и годом рождения или смерти.
} 
учитывали по последнему дню, когда смертность после максимума превышала LOWESS (исключение составили самоубийства - см. ниже).

Избыточные смерти (выше линии регрессии) оценивали: 1) по абсолютной величине; 2) в процентах по доле в сумме избыточной смертности; 3) в процентах по отношению к непраздничной («естественной») смертности (ниже линии регрессии). Последнее представляется главным показателем «патогенности» дней рождения - насколько избыточная смертность превысила смертность в будни.

Корреляция выполнена по методу Кендалл- $\tau$, дающему более точные показатели в сравнении с методом Спирмена, значения которого всегда выше.

\section{РезУЛЬтАТЫ}

Ряд общей смертности со скользящей средней LOWESS представлен на рисунке 1, а вычисления на этой основе - в таблице 1 .

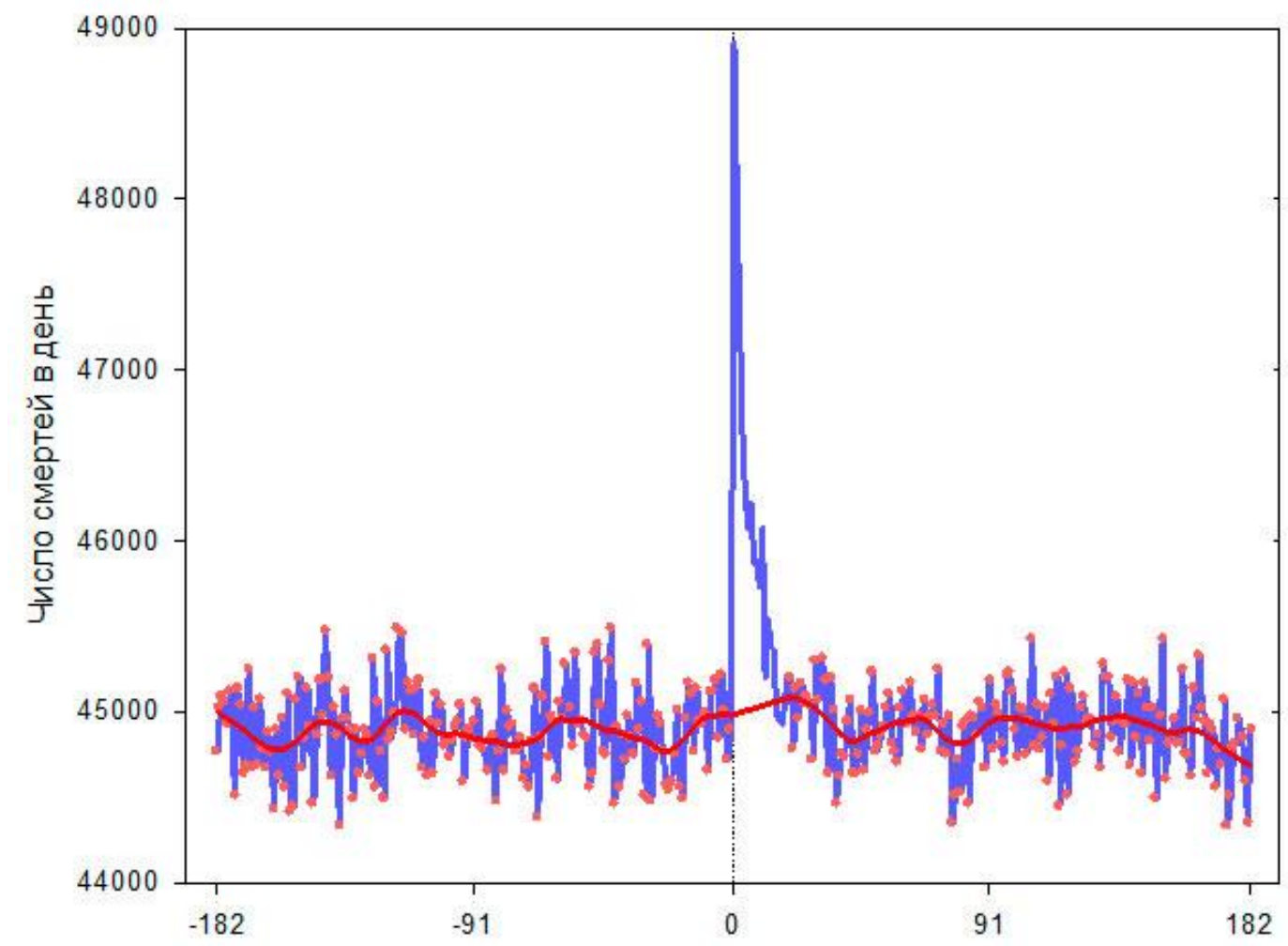

\section{Рисунок 1. Ежедневное число смертей в России по отношению ко дню рождения, принятому за 0 ( \pm 182 дня; сумма 2011-2019 гг.).}

Источник: Составлено авторами.

Примечание: Красная линия - скользящая средняя LOWESS, экстраполированная на праздничные дни.

Непраздничные дни помечены красными точками

На рисунке 1 прежде всего обращает внимание значительный рост смертности в день рождения (48,9 тыс. в день). В последующие 14 дней смертность прогредиентно снижается и достигает уровня непраздничной смертности (линия LOWESS). За эти 15 дней избыточная 
смертность составляет 19,7 тыс. или 3,5\% от «естественной» смертности, характерной для непраздничных дней (сумма 2011-2019 гг.; таблица 1). Число избыточных смертей только в день рождения составило 4,0 тыс. или пятую часть $(+21,1 \%$ по отношению смертности в будни). Детальная картина смертности в связи с днем рождения представлена на рисунке 2 , который является фрагментом рисунка 1.

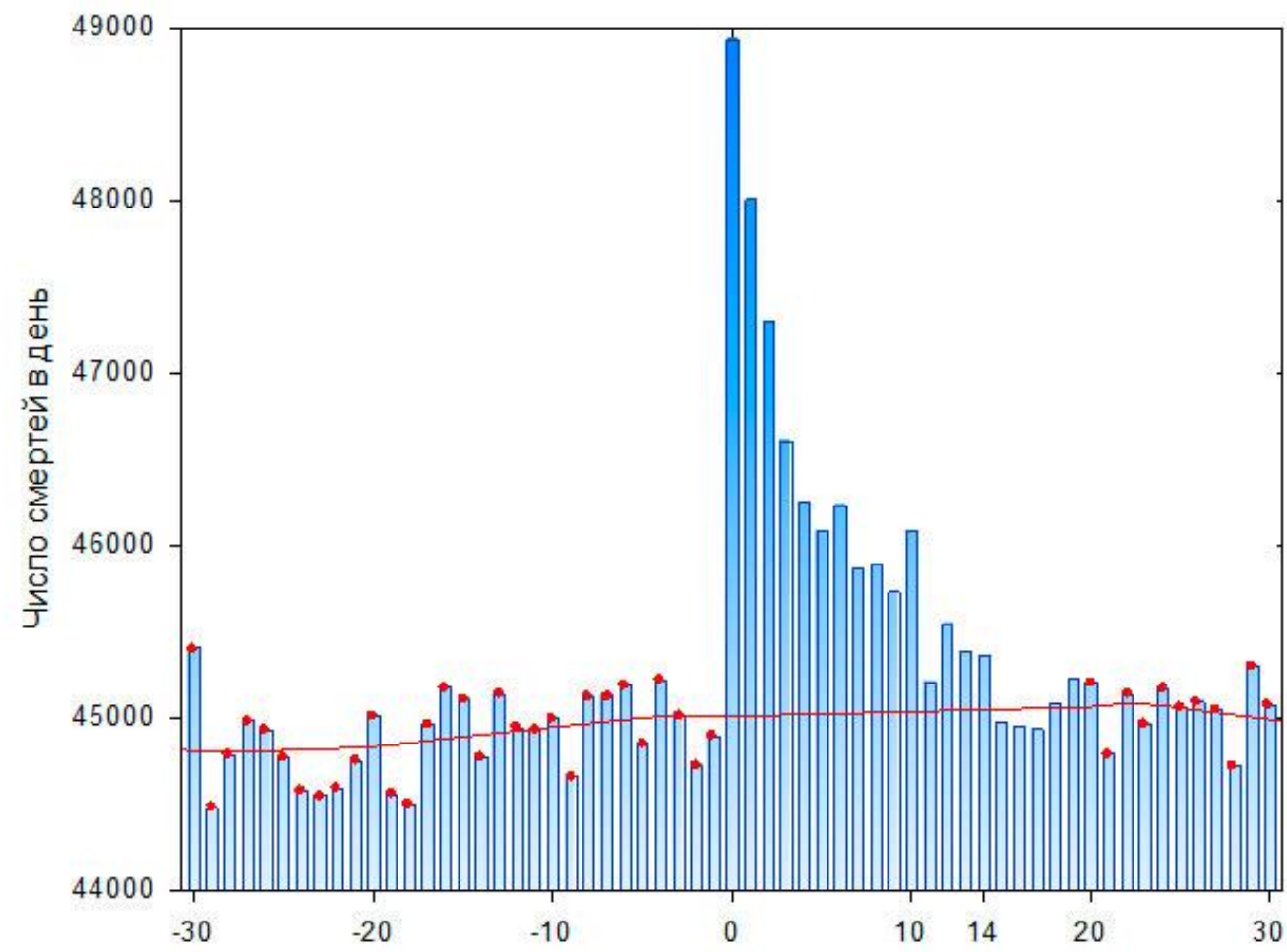

Рисунок 2. Ежедневное число смертей в России по отношению ко дню рождения, принятому за 0 ( \pm 30 дней; сумма 2011-2019 гг.)

Источник: Составлено авторами.

Примечание: Красная линия - скользящая средняя LOWESS для непраздничных дней, экстраполированная на праздничные дни дней. Непраздничные дни помечены красными точками. На горизонтальной оси 14 - последний день избыточной смертности.

Большой разброс имела продолжительность избыточной смертности разных классов, самой короткой она была при новообразованиях (1 день). Избыточная смертность от соматических причин, которая составляла почти $60 \%$, укладывалась в 2 недели, а самой продолжительной избыточная смертность была при самоубийствах (25 дней).

Для дальнейшего анализа важно отметить, что общая смертность (столбец 1 в таблице 1), за вычетом естественной (2), значимо коррелирует с естественной $(2 ; r=0$, $0,829, p=0,0000, n=15)$, а избыточная (3) - с естественной $(2 ; 0,829, p=0,0000, n=15$; все расчеты по Кендалл- $\tau$; равенство корреляций). Первая корреляция свидетельствует, что с помощью LOWESS вычисления «естественной» (непраздничной) смертности в праздничные дни сделаны корректно, а вторая - что избыточная смертность в праздники в целом пропорциональна «естественной» (непраздничной). Корректность вычисления «естественной» смертности в день рождения подтверждается сравнением с ранее 
полученными показателями «естественной» смертности в новогодние праздники (Немцов, Фаттахов 2021: в печати), которые несколько больше за счет погодных условий.

\section{Таблица 1. Диагностический состав избыточной смертности в связи с днями рождения в 2011-2019 гг.}

\begin{tabular}{|c|c|c|c|c|c|c|c|c|}
\hline \multirow[t]{2}{*}{ Причины } & \multirow{2}{*}{ 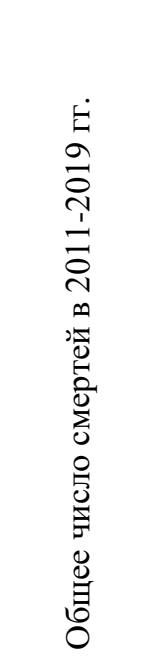 } & \multirow{2}{*}{ 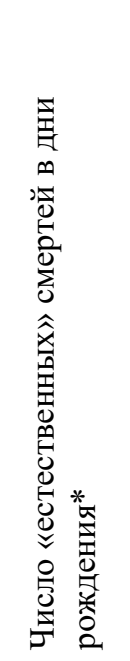 } & \multirow{2}{*}{ 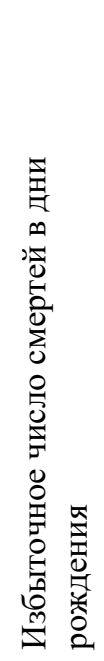 } & \multicolumn{2}{|c|}{ 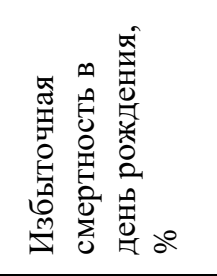 } & \multirow{2}{*}{ 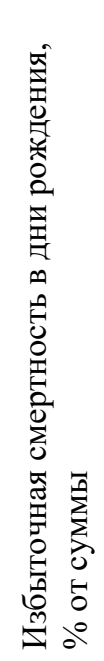 } & \multirow{2}{*}{ 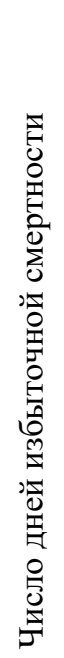 } & \multirow[b]{2}{*}{ 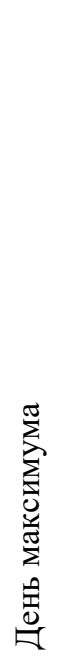 } \\
\hline & & & & 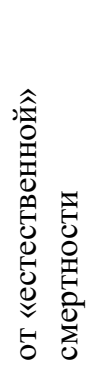 & 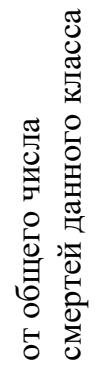 & & & \\
\hline Болезни системы кровообращения & 8330764 & 320320 & 9147 & 2,9 & 0,11 & 46,5 & 14 & 1 \\
\hline Болезни органов дыхания & 606942 & 23100 & 1480 & 6,4 & 0,24 & 7,5 & 14 & \\
\hline Болезни органов пищеварения & 839211 & 34755 & 937 & 2,7 & 0,11 & 4,8 & 15 & 4 \\
\hline Новообразования & 2632333 & 7218 & 396 & 5,5 & 0,02 & 2,0 & 1 & 1 \\
\hline Внешние причины & 1494224 & 64784 & 5175 & 8,0 & 0,35 & 26,3 & 16 & 2 \\
\hline Другие причины & 2213907 & 109260 & 2540 & 2,3 & 0,11 & 12,9 & 18 & 1 \\
\hline Всего** & 16117381 & 559437 & 19675 & 3,5 & 0,12 & 100,0 & 15 & 1 \\
\hline Внешние причины -в & & & & & & & & \\
\hline Алкогольные отравления & 141414 & 4290 & 1016 & 23,7 & 0,72 & 5,2 & 11 & 2 \\
\hline Убийства & 108117 & 1184 & 296 & 25,0 & 0,27 & 1,5 & 4 & 2 \\
\hline Самоубийства & 217108 & 14425 & 1310 & 9,1 & 0,60 & 6,7 & 25 & 1 \\
\hline ДТП & 214134 & 2316 & 481 & 20,8 & 0,22 & 2,4 & 4 & 2 \\
\hline Падения & 73645 & 1167 & 219 & 18,8 & 0,30 & 1,1 & 6 & 1 \\
\hline Утопления & 55943 & 700 & 338 & 48,3 & 0,60 & 1,7 & 5 & 1 \\
\hline Пожар & 46889 & 630 & 158 & 25,1 & 0,34 & 0,8 & 4 & 1 \\
\hline $\begin{array}{l}\text { Повреждения с неопределенными } \\
\text { намерениями }\end{array}$ & 363565 & 9018 & 800 & 8,9 & 0,22 & 4,1 & 9 & \\
\hline
\end{tabular}

Примечание: *_«Естественные» смерти - смерти, которые случились бы в отсутствии праздника.

** - За исключением «инфекционные заболевания».

Таблица 1 показывает, что избыточная смертность в 2011-2019 гг. составила 19675 человек или 2,2 тыс. в год.

Наибольший вклад в избыточную смертность вносят болезни системы кровообращения (46,5\%), что близко к доле этих смертей в общей смертности $(51,7 \%)$. При этом прирост смертности этого класса в день рождения невелик по отношению к «естественным» смертям (2,9\%), а это значит, что сравнительно невелико воздействие праздника на этот класс смертей. По этому показателю значительнее увеличились болезни органов дыхания $(6,4 \%)$ и органов пищеварения $(4,8 \%)$, хотя их вклад в избыточную смертность был значительно меньше (7,5 и 4,8\% соответственно). Неожиданным был кратковременный рост в день рождения смертности при новообразованиях (на 5,5\%), 
хотя их прирост к общему числу смертей при новообразованиях был наименьшим $(0,02 \%)$, как и продолжительность прироста (1 день; таблица 1).

По доле в избыточной смертности внешние причины следовали за болезнями системы кровообращения (26,3\%), хотя этот класс смертей был относительно невелик в общей (непраздничной) смертности (9,3\%; рисунок 3$)$. Как видно, в связи с днем рождения рост смертей от внешних причин среди других классов был наибольшим (почти в 3 раза с 9,3 до 26,3\%). А это значит, что главный урон в связи с днем рождения приходится на внешние причины (рисунок 3). Это заставило исследовать данный класс подробнее, разложив входящие в него смерти на составляющие, что принесло много неожиданных результатов.
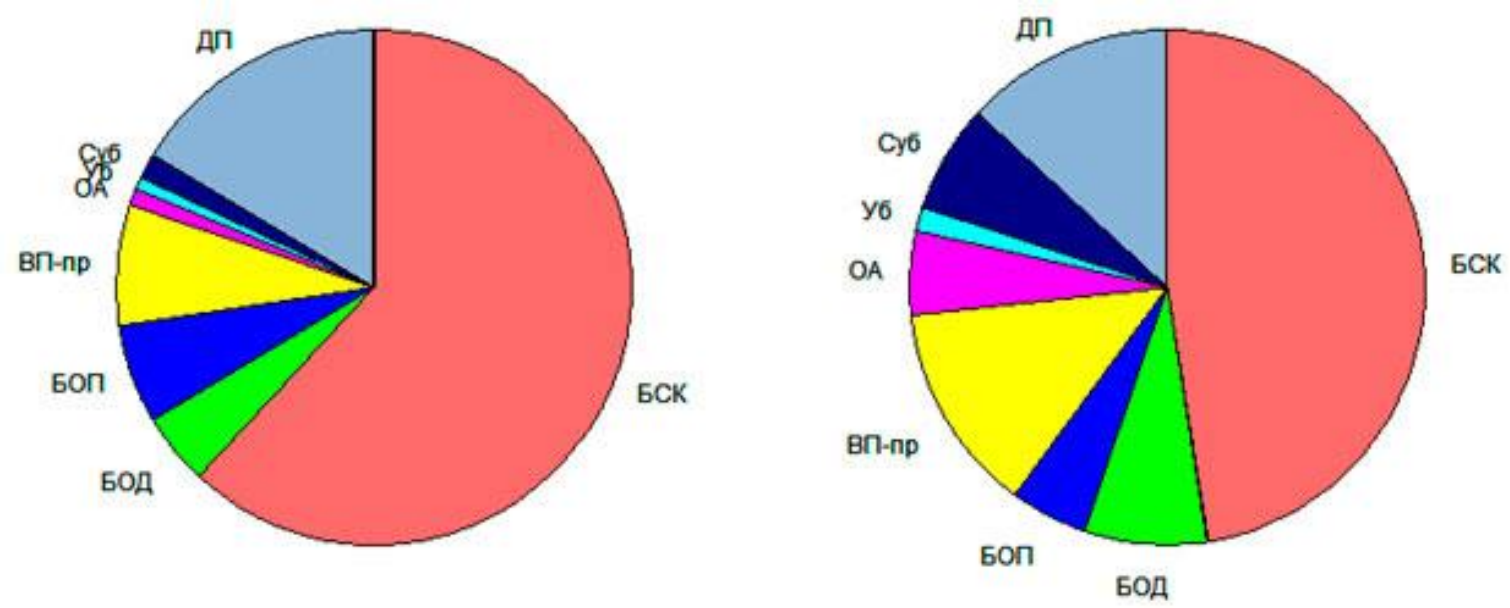

\section{Рисунок 3. Соотношение смертей по причинам: слева общая (непраздничная), справа избыточная смертность в праздники дня рождения}

Источник: Составлено авторами.

Примечание: БСК - болезни системы кровообращения, БОД - болезни органов дыхания, БОП - болезни органов пищеварения, ВП-пр - внешние причины прочие, ОА - отравления алкоголем, Уб - убийства, Суб - самоубийства, ДП - другие причины.

В день рождения практически в 1,5 раза по сравнению с буднями увеличились смерти при утоплении (на 48,3\%; таблица 1, столбцы 3 и 4), хотя их вклад в избыточную смертность был небольшим (1,7\%). С 19 до 25\% выросли алкогольные отравления, убийства, смерти на дорогах, при падении и пожарах. Суммарный вклад в избыточную смертность этих пяти видов смертей составил 11,0\%.

С помощью линейной регрессии было исследовано соотношение избыточной смертности в праздники и непраздничной смертности сначала в отношении отдельных видов смертности от внешних причин (рисунок 4). При этом обнаружилось, что прирост этих смертей был в целом пропорционален их доле в непраздничной смертности. Исключение составили смерти при отравлении алкоголем, которые существенно отклонились от пропорциональной зависимости $(p<0,01)$, характерной для остальных внешних причин (рисунок 4). Расчеты показывают, что в случае пропорциональности отравления алкоголем составили бы $521 \pm 104$ избыточных смертей против реальных 1016 , т. е. в 2 раза меньше того, что наблюдалось в действительности. Это может означать, что на 
смерти при отравлении алкоголем действуют дополнительные по отношению к другим внешним причинам факторы. Аналогично были исследованы 6 больших классов смертей, избыточная смертность пяти из них была пропорциональна естественной смертности, исключение составили внешние причины, которые были существенно больше величины, ожидаемой на основе непраздничной смертности.

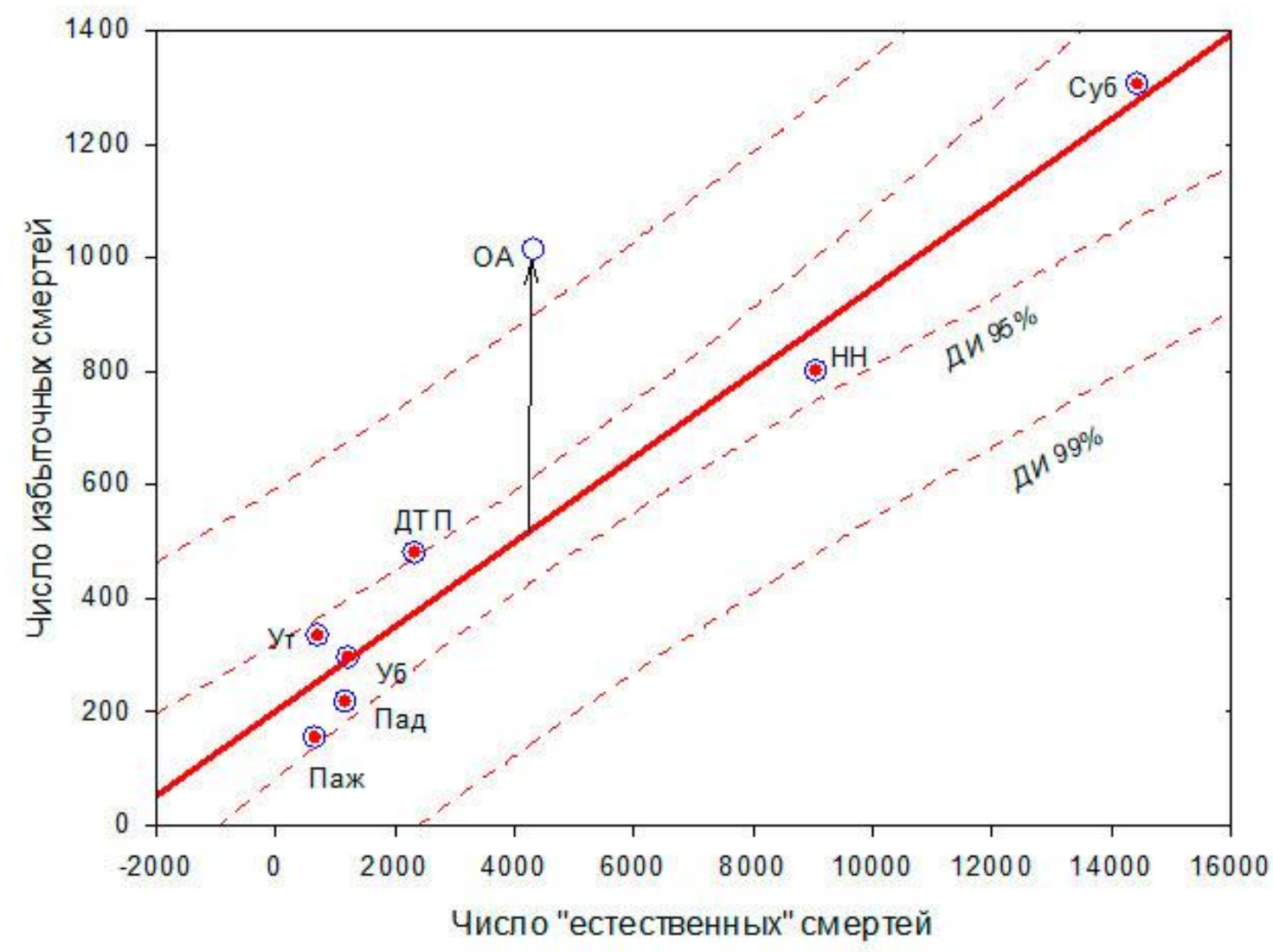

\section{Рисунок 4. Регрессия избыточной («естественной») в праздники по непраздничной смертности смертей от внешних причин с исключением отравления алкоголем}

Источник: Составлено авторами.

Примечание: Красная линия - регрессия для причин, помеченных красной точкой, пунктир доверительные интерваль 95 и 99\%. Суб - самоубийства, ОА - отравления алкоголем, ННнеопределенные намерения (внешние причины), ДТП - дорожно-транспортные, Ут - утопления, Уб - убийства, Пад - падения, Паж - воздействие огнем и пламенем, ДИ - доверительный интервал. Стрелка - мера отклонения ОА от регрессии остальных видов смертей.

Таблица 2. Показатели линейной регрессии избыточной смертности в дни рождения по непраздничной смертности

\begin{tabular}{c|c|c|c|c|c}
\hline $\begin{array}{c}\text { Виды смертей } \\
(\mathrm{n})\end{array}$ & $\begin{array}{c}\text { Константа } \\
\mathrm{a}\end{array}$ & $\begin{array}{c}\text { Коэффициент } \\
\mathrm{b}\end{array}$ & $\begin{array}{c}\text { Корреляция } \\
\mathrm{R}\end{array}$ & $\begin{array}{c}\text { Детерминанта } \\
\mathrm{R}^{2}\end{array}$ & $\begin{array}{c}\text { Значимость } \\
\mathrm{p}\end{array}$ \\
\hline Основные классы без ВП (5) & 389,1 & 0,027 & 0,987 & 0,975 & 0,0000 \\
Основные виды ВП без ОА (7) & 201,0 & 0,075 & 0,981 & 0,962 & 0,0001 \\
\hline
\end{tabular}

Примечание: ВП-внешние причины, ОА-отравления алкоголем.

К этому следует добавить, что регрессия избыточной смертности от внешних причин по непраздничной смертности значительно круче, чем наклон у соматических классов 
(в 3 раза: 0,075 против 0,023, таблица 2). Из этого следует, что смерти от внешних причин значительно больше зависят от «фактора дня рождения», чем классы соматической смертности.

На рисунке 5 следует отметить, что максимум самоубийств приходится на день рождения, а прочие составляющие класса внешних причин - на 2-й день после дня рождения. Кроме того, для самоубийств характерны 2 дополнительных пика - на 7-й и 15-й дни после дня рождения.

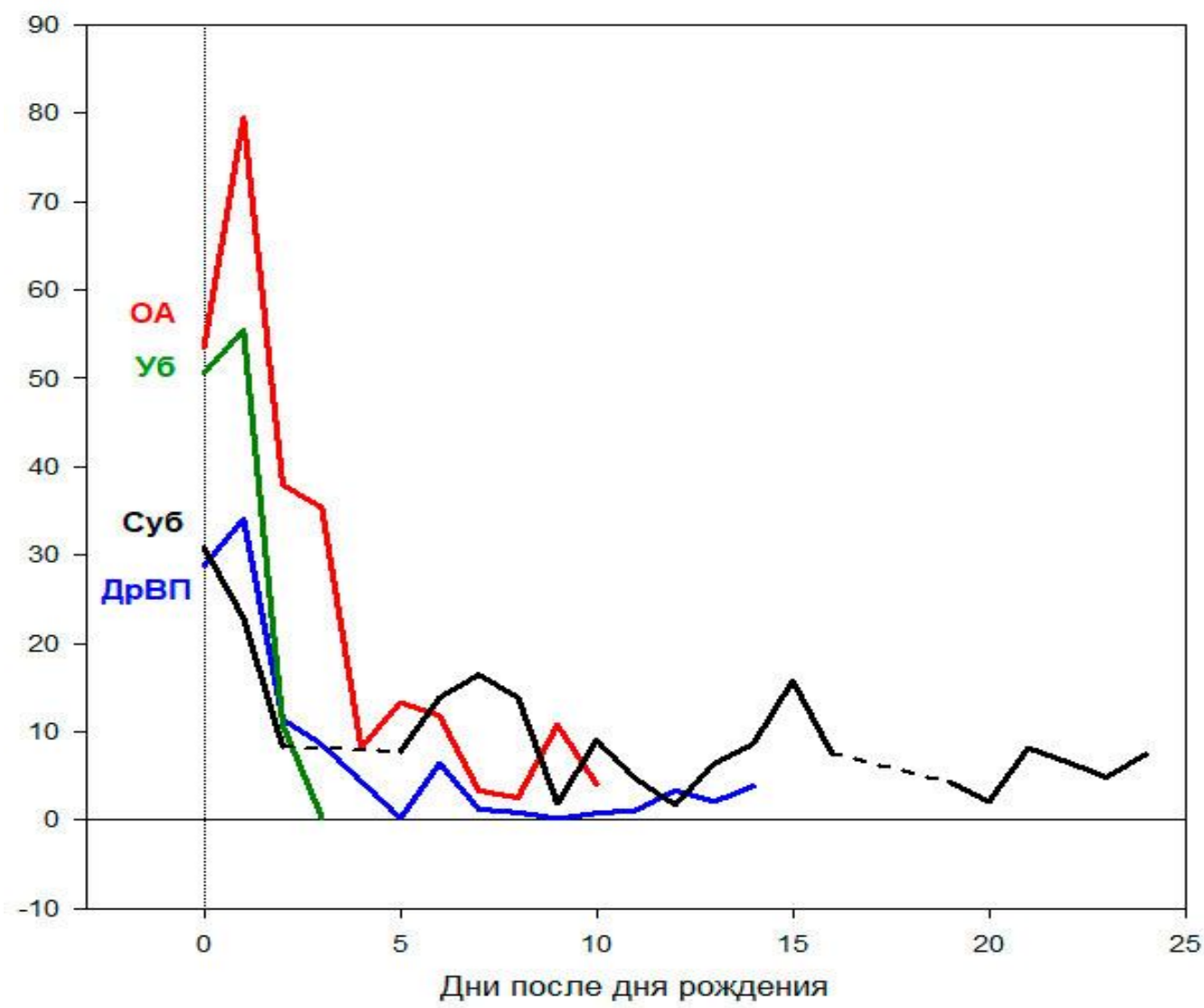

\section{Рисунок 5. Динамика смертности в связи с днем рождения, \% к LOWESS}

Источник: Составлено авторами.

Примечание: 0 на горизонтальной оси - день рождения, на вертикальной оси - LOWESS, приведенная к 0 на протяжении 25 дней. ОА - отравления алкоголем, Уб - убийства, Суб - самоубийства (пунктир пропущенное значение), ДрВП-другие внешние причины.

Здесь следует отметить еще одну особенность самоубийств: после суммирования годичных отрезков суммарный ряд имел довольно большую дисперсию. Это возможно обусловлено множественной периодической составляющей самоубийств (сезонной, месячной, недельной, праздничной и даже знаков зодиака (Deisenhammer, Stiglbauer, Kemmler 2018: 93)). Это заставило отказаться от единого способа определения окончания периода избыточной смертности (см. Методика) и считать окончанием не 3-й, а 25-й день (рисунок 6). 


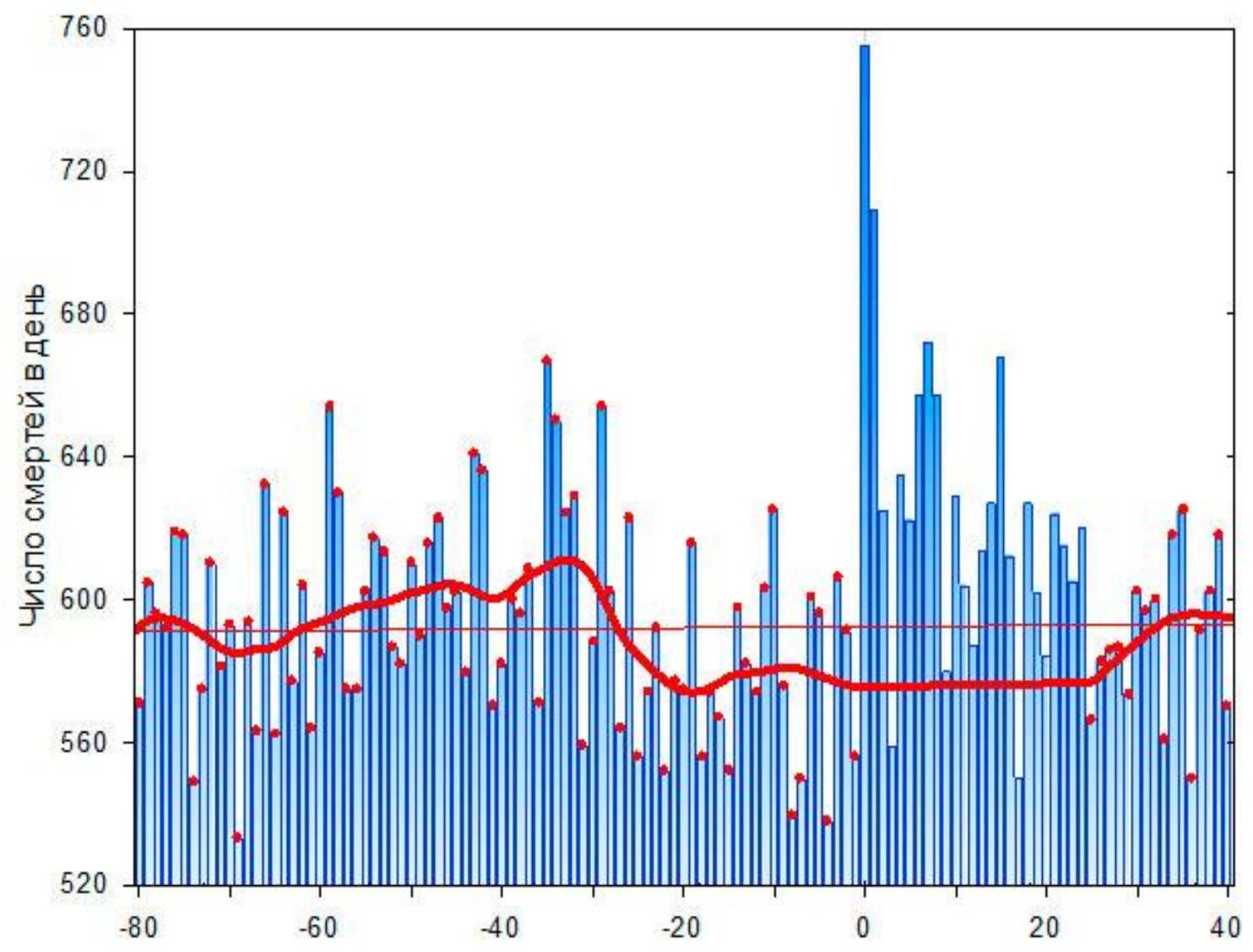

Рисунок 6. Ежедневное число самоубийств в России по отношению ко дню рождения, принятому за 0 (-80 $\div+40$ дней; сумма 2011-2019 гг.)

Источник: Составлено авторами.

Примечание: Красная толстая линия - скользящая средняя LOWESS для непраздничных дней, экстраполированная на праздничные дни. Непраздничные дни помечены красными точками. Тонкая прямая - линейная регрессия для того же ряда.

Еще одна особенность самоубийств состоит в том, что увеличение их количества начинается за 2 месяца до дня рождения (рисунок 5). Пик этого роста пришелся на 35-й день, а избыточная смертность в этот период (с 59-го по 28-й день) составила 494 человека или 2,6\% от «естественной» смертности. После этого началось снижения показателя вплоть до дня рождения. В день рождения избыточная смертность составила 175 человек, а всего за 25 дней - 1310 человек (таблица 1). На рисунках 5 и 6 можно видеть, что в период избыточной смертности существует цикличность с дополнительными максимумами на 7-й и 15-й дни после дня рождения.

Представляет интерес сравнение показателей избыточной смертности в день рождения с аналогичными данными в связи с Новым годом, который исследован ранее (Немцов, Фаттахов 2021: в печати). И те, и другие данные выполнены на одном исходном материале и представлены в процентах избыточной смертности к смертности «естественной» (рисунок 7). 


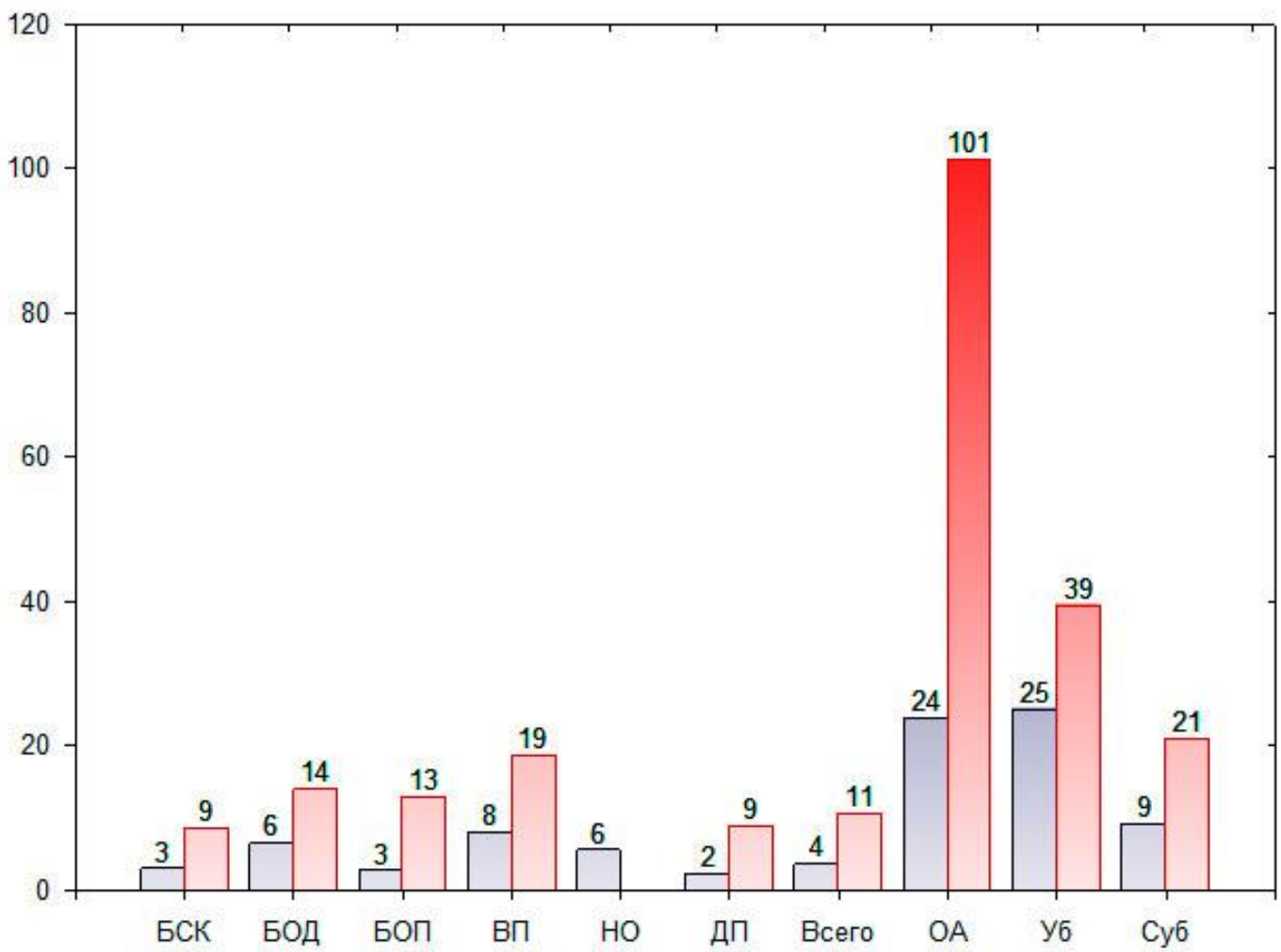

Рисунок 7. Избыточная смертность по причинам в дни рождения (синие) и в Новый год (красные*), \%

Источник: Составлено авторами. *-(Немцฺв, Фаттахов 2021: в печати, таблица 2).

Примечание: Вертикальная ось и числа на графике - проченты по отношению к непраздничной смертности. За 0 принят уровень непраздничной смертности. БСК - болезни системы кровообращения, БОД - болезни органов дыхания, БОП - болезни органов пищеварения, ВП - внешние причины, НО - новообразования, ДП - другие причины, Всего - общее число, ОА - отравления алкоголем, Уб-убийства, Суб-самоубийства.

Как видно, избыточная смертность в день рождения и в Новый год пропорциональны $(r=0,778, p=0,004, n=9)$, а главное отличие - избыточная смертность в Новый год от всех причин существенно, в 2-4 раза больше, чем в день рождения. Исключение составила смертность от новообразований, которая увеличилась в день рождения, но никак не проявила себя избыточной смертностью в Новый год.

\section{ОБСУЖДЕНИЕ}

Недавно в России, как и в других странах мира, описан рост смертности во время государственных праздников, но особенно большой - в связи с праздником Нового года (Немцов и др. 2021:16). Высказано предположение, что особый статус Нового года связан с тем, что этот праздник воспринимается людьми как временной рубеж с надеждой на новые блага. В стране широко отмечается другой рубежный праздник - день рождения. Это стало поводом исследовать этот праздник в предположении, что это событие также будет сопровождаться ростом смертности. Действительно, в работе 2021 г. (Немцов и др. 2021:16) впервые в России зафиксирован значительный рост смертности в связи с днем 
рождения. В настоящей работе на том же материале избыточная смертность в эти праздники распределена по диагностическим категориям.

В целом в связи с днем рождения в 2011-2019 гг. дополнительно погибло 19,7 тыс. человек или 2,2 тыс. в год. Это составляет 3,5\% от «естественной» смертности, характерной для непраздничных дней (таблица 1). В этот период только в день рождения избыточная смертность составила 4,0 тыс. или пятую часть (21,1\%). Для сравнения в США за 13 лет (1998-2011 гг.) избыточная смертность в день рождения составила 4590 случаев (Реп̃a 2015: 59) или 353 в год.

После аналогичного анализа избыточной смертности в Новый год (Немцов и др. 2021:16) не было неожиданностью, что в день рождения основной вклад в избыточную смертность вносят болезни системы кровообращения (46,5\%; таблица 1). Однако приращение в праздники этого класса смертей по отношению к «естественной», непраздничной смертности невелико, всего на 2,9\%. Это свидетельствует о том, что патогенное действие дней рождения на этот класс смертей невелико. Такое приращение мало влияет на соотношение долей избыточной смертности в праздники и не праздничные дни (46,5\% против 51,7\%), но даже такая небольшая разница связана с тем, что в день рождения резко увеличивается доля смертей от внешних причин (рисунок 3 ).

Внешние причины в непраздничные дни составляли 9,3\%, а в день рождения вырастают на 8,0\% и составляют в избыточной смертности более четверти $(26,8 \%$; рисунок 3). 8\% - это самый больший прирост среди других классов смертей. В связи с этим может возникнуть вопрос, что тяжелее обходится населению в день рождения: 8\%ный прирост и 27\%-ный вклад в избыточную смертность внешних причин или 3\%-ный прирост, но 47\%-ный вклад при болезнях системы кровообращения, 5 тыс. смертей первых или 9 тыс. вторых? Возможно, ответить помог бы возрастной анализ тех и других, а пока примем, что оба класса смертей являются ведущей причиной избыточной смертности в день рождения. Это в целом.

Однако негативные последствия праздника определяются более всего приростом смертности по отношению к показателям в будни («естественные» смерти). При таком подходе внешние причины становятся первыми (прирост 8,0\% против 2,3-5,5\% остальных классов; таблица 1). Если ориентироваться на прирост смертей, то в составе внешних причин лидируют утопления (+48\%; таблица 1$)$, за ними следуют гибель в пожарах и убийства (по $+25 \%)$, отравления алкоголем $(+24 \%)$ и ДТП $(+21 \%)$. Замыкают этот ряд смерти с неопределенными намерениями и самоубийства (по $+9 \%)$. Однако по количеству смертей в избыточной смертности от внешних причин доминируют самоубийства (1310 человек), они же доминируют и по продолжительности (25 дней). Особенность самоубийств состоит в том, что рост смертности начинается за 2 месяца до дня рождения (рисунок 6), снижается за 20 дней до него и резко увеличивается в этот день. Цикличность сохраняется в последующие дни с периодом в неделю. Сложная динамика самоубийств в связи с днем рождения характерна не только для России, она была описана в Японии (см. Введение).

Существует представление о меланхолии в связи с днем рождения (Birthday blues (Williams et al. 2011:134)) - так называют состояние, возникающее у рефлексирующих 
людей перед днем рождения. Но бывает и более тяжелый аналог меланхолии - депрессия дня рождения (Birthday depression (Mukherjee, Kumar 2017: 3)). Оба состояния иногда разрешаются самоубийством, первое изредка, второе часто. В Японии также как в России период самоубийств шире одного дня рождения (Motohashi 2012: 1282), но в России, если судить по смертности, самоубийства начинают расти за 2 месяца до этого (рисунок 6), и это должно определять превентивную тактику и выявление тоскливого настроения. Тем более, что люди в связи со своим днем рождения ищут медицинской помощи даже у терапевтов (Handysides 2011: 575).

По количеству избыточной смертности после самоубийства (1310) следовали смерти при отравлении алкоголем (1016 в 2011-2019 гг.). В отличие от остальных классов и видов смертей, которые прирастали в день рождения пропорционально непраздничным смертям, эти смерти имели уникальную особенность - существенное отклонение от этой закономерности в сторону двукратного увеличения по отношению линии регрессии (рисунок 6). Это означает, что на рост этих смертей, в отличие от других, действуют какието дополнительные факторы праздника. Помимо прочего это может быть двукратное увеличение либо потребления, либо числа тяжелых потребителей. Скорее второе расширение круга тяжелых потребителей в связи с праздником. Еще резче эта закономерность проявлялась в Новый год (Немцов, Фаттахов 2021: в печати).

По приросту в день рождения с отравлениями алкоголем и самоубийствами сопоставимы были утопления, убийства, гибель в пожарах, ДТП и падения с высоты: от 19\% (падения с высоты) до 48\% (утопления; таблица 1). Несмотря на большой прирост в целом смерти этих пяти видов составили 29\% избыточной смертности от внешних причин. Но тут следует вспомнить, что внешние причины смертей - яркий пример предотвратимых смертей. По сути дела, в день рождения предотвратимыми являются и все другие классы смертей, как описанные выше смерти от болезней системы кровообращение, так и от болезней органов дыхания и пищеварения. Остаются нерешенным вопрос, почему в условиях праздничного застолья с характерным для населения страны перееданием смерти от болезней органов пищеварения дали сравнительно небольшой прирост? Возможно, ответ появится, если эти причины детализировать по возрастам, но скорее всего это связано с тем, что доминирующим патогенным фактором в праздники является не переедание, а злоупотребление алкоголем, которое вносит вклад во все классы смертей. Это неоднократно показано в отношении убийств (например, (ВО3 2006; Pridemore 2002: 1921)), самоубийства (например, (Радкевич, Кабанкин, Радкевич 2017: 33)), сердечно-сосудистую смертность (например, (Corrao et al. 2000:1505)) и болезни органов дыхания (Simou, Britton, Leonardi-Bee 2018: e022344). Конечно, есть различия зависимой от алкоголя смертности в праздники и будни. Так, вне связи с праздниками сердечно-сосудистая смертность имеет значительные, около трех лет лаги по отношению к динамике потребления водки, но не других напитков (Разводовский 2006: 37). Но это отличие обусловлено тем, что праздничное потребление много больше потребления в будни, что и приводит к избыточной смертности в первые дни праздника.

В исследовании обнаружилось, что значительная доля избыточной смертности в праздники приходится на повреждения с неопределенными намерениями (4,1\%; таблица 1$)$. 
Это несколько меньше, чем при самоубийствах и отравлении алкоголем, но больше, чем остальные виды смертей от внешних причин. Скорее всего, это застарелая проблема российской статистики - сокрытие или неточная диагностика причин смерти (Семенова и др. 2004; 11), и это в первую очередь касается внешних причин (Лопаков 2011). Ели бы не это, распределение по диагнозам смертей от внешних причин могло быть другим, в первую очередь в отношении социально значимых причин, самоубийства, убийства и отравления алкоголем.

Последнее, что требуется обсудить, место дней рождения в ряду других праздников по размерам потерь. Ранее было показано, что 7 государственных праздников сопровождаются ростом смертности, 3 из них в январе (01.01, 07.01 и 14.01), по одному в феврале и марте (23.02 и 08.03) и 2 в мае (01.05 и 09.05 (Немцов и др. 2021:16)). Избыточную смертность в январе трудно разложить на отдельные праздники, потери одного слагаются с потерями следующего, а в целом она составила 6,3 тыс. в год с максимумом 1 января (2 тыс. человек). В остальные праздники избыточная смертность была много меньше (0,5-0,8 тыс. в год). Из этого следует, что избыточная смертность в дни рождения (2,2 тыс. в год) занимает промежуточное положение между новогодними и остальными праздниками. По диагностическому составу избыточная смертность в дни рождения практически не отличается от новогодних праздников (Немцов, Фаттахов 2021: в печати) и в целом пропорциональна. Главное отличие в размерах прироста почти по всем диагностическим группам - в Новый год прирост был значительно больше (рисунок 7). Исключение составили новообразования, которые проявили себя кратковременным приростом смертности в день рождения, но не в Новый год. Таким образом, по количеству избыточных смертей главным праздником в стране является Новый год. Связать различие избыточной смертности в Новый год и дни рождения с различием погодных условий трудно, так как низкая температура в январе распределения равномерно в течение месяца, а максимум смертности приходится на 1 января и заканчивается через 3 недели. Однако вполне исключить влияние погоды нельзя, так как в Новый год увеличивается количество замерзших в состоянии алкогольного опьянения. Но ситуация в связи с днем рождения также требует разъяснения, а также информационной поддержки. В этом и состоит значение работы - обнаружить неизвестную до сих пор, но застарелую проблему, обратить на нее внимание и предоставить материал для пропагандистской работы.

\section{ОГРАНИЧЕНИЯ ИССЛЕДОВАНИЯ}

Аппроксимация непраздничной смертности в праздники посредством линейной функции могла не соответствовать реальной динамике «естественной» смертности, однако не было никаких предпосылок выбрать какую-либо другую функцию как более адекватную. Авторам также не удалось найти единый формализованный метод определения окончания избыточной смертности после дня рождения. Однако применение других функций в первом случае и других параметров во втором составляло доли процента и этим можно пренебречь. 


\section{Выводы}

1. Дни рождения сопровождаются избыточной смертностью, которая составляет $3,5 \%$ от смертности в будни или 2,2 тысячи в год.

2. Главными составляющими избыточной смертности являются болезни системы кровообращения (46,5\%) и внешние причины $(26,3 \%)$.

3. Прирост по количеству смертей в день рождения был пропорционален смертности в будни. Исключение составили смерти при отравлении алкоголем, которые приросли в 2 раза больше, чем можно было ожидать по смертности в будни.

4. В связи с днем рождения наибольший прирост наблюдался у отдельных видов смертей от внешних причин: утопления (на 48\%), убийства и при пожарах (по 25\%), ДТП (на 21\%), падения с высоты (на 19\%).

5. Главным фактором избыточной смертности в день рождения был рост злоупотребления крепкими алкогольными напитками.

6. По размерам избыточной смертности дни рождения занимают промежуточное положение между январскими и остальными праздниками.

\section{ЛИТЕРАТУРА}

Лопаков К.В. (2011). Оценка достоверности кодирования причин смерти (по материалам пилотного исследования). Социальные аспекты здоровья населения, 2.

ВОЗ (2006). Межличностное насилие и алкоголь в Российской Федерации. Всемирная организация здравоохранения. Европейское региональное бюро. https://apps.who.int/iris/bitstream/handle/10665/107355/e88757r.pdf;jsessionid=9A8A33451 C7C2F78D16AA55218F945AA? sequence $=2$

Немцов А.В., Фаттахов Т.А. (в печати). Диагностический и возрастной состав избыточной смертности в связи с январскими праздниками в России. Население и экономика.

Немцов А.В., Симонов А.Н., Фаттахов Т.А., Гридин Р.В. (2021). Избыточная смертность в России в праздничные дни. Демографическое обозрение, 8(1), 16-43.

DOI:10.17323/demreview.v8i1.12392

Радкевич Л.А., Кабанкин А.С., Радкевич Д.А. (2017). Смертность от суицида и алкоголизма, зависимая от уровня потребления алкогольных напитков. Research'n Practical Medicine Journal, 4(1), 33-39. DOI:10.17709/2409-2231-2017-4-1-4

Разводовский Ю.Е. (2006). Алкоголь и сердечно-сосудистая смертность в Беларуси. Журнал ГрГМУ, 4, 37-42.

Семенова В.Г., Гаврилова Н.С., Евдокушкина Г.Н., Гаврилов Л.А. (2004). Качество медико-статистических данных как проблема современного российского здравоохранения. Общественное здоровье и профилактика заболеваний, 2, 11-19.

Abel E., Kruger M. (2009). Mortality Salience of Birthdays on Day of Death in the Major Leagues". Death Studies, 33 (2), 175-184. DOI:10.1080/07481180802138936.

Ajdacic-Gross V., Knopfli D., Landolt K. et al. (2012). Death has a preference for birthdays - an analysis of death time series. Annals of Epidemiology, 22(8), 603-606.

DOI:10.1016/j.annepidem.2012.04.016. 
Anderson M. (1975). Relationship between month of birth and month of death in the elderly. British Journal of Preventive \& Social Medicine, 29(3), 151-156.

DOI:10.1136/jech.29.3.151.

Bovet J., Spagnoli J., Sudan C. (1997). Mortalité et anniversaire de naissance. (in French; Mortality and birthday). Soz Präventivmed, 42(3), 155-161. DOI:10.1007/BF01300566

Cleveland W., Devlin S. (1988). Locally-Weighted Regression: An Approach to Regression Analysis by Local Fitting. Journal of the American Statistical Association, 83, 596-610. DOI: $10.2307 / 2289282$

Corrao G., Rubbiati L., Bagnardi V., Zambon A., Poikolainen K. (2000). Alcohol and coronary heart disease: a meta-analysis. Addiction, 95(10),1505-1523. DOI:10.1046/j.13600443.2000.951015056.x.

Deisenhammer E.A., Stiglbauer C., Kemmler G. Zeitliche (2018). Aspekte von Suiziden Häufigkeit von Suiziden in Beziehung zu Geburtstag, Feiertagen, Wochentagen, Jahreszeit sowie Geburtsmonat und Sternzeichen (In German: Time-related aspects of suicides - suicide frequency related to birthday, major holidays, day of the week, season, month of birth and zodiac signs. Neuropsychiatr, 32(2), 93-100. DOI:10.1007/s40211-018-0260-7

Doblhammer G. (1999). Longevity and month of birth: Evidence from Austria and Denmark. Demographic Research, 1 (3), 1-22. DOI:10.4054/DemRes.1999.1.3.

Handysides S. (2011). Characteristics of patients who consult their GP on their birthdays. $\mathrm{Br} J$ Gen Pract., 61(590), 575-576. DOI:10.3399/bjgp11X593974.

Matsubayashi T., Lee Mj., Ueda M. (2019). Higher Risk of Suicide on Milestone Birthdays: Evidence from Japan. Sci Rep 9, 16642. DOI:10.1038/s41598-019-53203-4

Medenwald D., Kuss O. (2014). Deaths and major biographical events: a study of all cancer deaths in Germany from 1995 to 2009. BMJ Open. 4(4): e004423. DOI:10.1136/bmjopen2013-004423.

Motohashi Y. (2012). Suicide in Japan. The Lancet, 9823, 1282-1283. DOI:10.1016/S01406736(11)61130-6

Mukherjee S., Kumar U. Theorizing Suicide: Multiple Perspectives and Implications for Prevention (2017). In Kumar U. (Ed.), Handbook of suicidal behaviour. Bangalore: Springer Nature (Chapter 1, pp. 3-22).

Peña P. (2015). A not so happy day after all: Excess death rates on birthdays in the U.S. Social Science \& Medicine, 126, 59-66. DOI:10.1016/j.socscimed.2014.12.014.

Phillips D., Van Voorhees C., Todd R. (1992). The Birthday: Lifeline or Deadline? Psychosomatic Medicine, 54(5), 532-542. DOI:10.1097/00006842-19920900000001

Pridemore W.A. (2002). Vodka and violence: alcohol consumption and homicide rates in Russia. American Journal of Public Health, 92(12), 1921-1930. DOI:10.2105/AJPH.92.12.1921

Reulbach U., Biermann T., Markovic K., Bleich S. (2007). The myth of the birthday blues: a population-based study about the association between birthday and suicide. Comprehensive Psychiatry, 48, 554-557. DOI:10.1016/j.comppsych.2007.06.006

Simou E., Britton J., Leonardi-Bee J. (2018). Alcohol and the risk of pneumonia: a systematic review and meta-analysis. BMJ Open, 8(8): e022344. DOI:10.1136/bmjopen-2018-022344

Stickley A., Sheng Ng. C., Inoue Y., Yazawa A., Koyanagi A., Kodaka M., DeVylder J., Watanabe Ch. (2016). Birthdays are associated with an increased risk of suicide in Japan: 
Evidence from 27,007 deaths in Tokyo in 2001-2010, Journal of Affective Disorders, 200, 259-265. DOI:10.1016/j.jad.2016.04.028

Vaiserman A., Grigoryev P., Belaya I., Voitenko V. (2003). Variation of mortality rate during the individual annual cycle. Biogerontolo, 4(4), 221-225. DOI:10.1023/A:1025168932058.

Williams A., While D., Windfuhr K., Bickley H., Hunt I.M., Shaw J., Appleby L., Kapur N. (2011). Birthday Blues, Examining the Association Between Birthday and Suicide in a National Sample. Crisis, 32, 134-142. DOI:10.1027/0227-5910/a000067 


\title{
BIRTHDAYS AS A SOURCE OF EXCESS MORTALITY: CAUSE OF DEATH COMPOSITION
}

\author{
ALEXANDER NEMTSOV, TIMUR FATTAKHOV
}

\begin{abstract}
Problem statement. Previously it was shown that in Russia and in the world, holidays are accompanied by an increase in mortality, mainly at Christmas and New Year's. But what about diagnoses of the excess mortality due to birthday celebrations?

Material and methods. To assess this, the data of 16.77 million deaths from 01/01/2011 to 12/31/2019 were examined for a possible correlation between birth and death dates. In all cases, the dates of birth and death were given the number of the day of the year. If these numbers coincided, the death case was assigned a value of 0 , and if they did not - the number of days of the difference with the birthday before or after this day, from \pm 1 to \pm 182 . This procedure was performed both for mortality in general and for 6 large classes of deaths and 8 types of external causes. Excess deaths on birthdays were estimated using the LOWESS moving average (locally weighted polynomial regression), which described non-holiday mortality, and on holidays its breaks were filled with linear regression, which served as an indicator of "natural" non-holiday mortality on holidays.
\end{abstract}

Results. A significant increase in birthday mortality was revealed (4.0 thousand per day for 9 years), and the total excess death rate associated with birthdays was 19.7 thousand, or $3.5 \%$ of "natural" mortality. The main contribution to excess mortality was made by diseases of the circulatory system (9.1 thousand) and external causes (5.2 thousand), and among external causes, by suicide (1.3 thousand), alcohol poisoning (1.0 thousand) and injuries with undetermined intent $(0.8$ thousand). Excess deaths on birthdays were proportional to non-holiday deaths, with the exception of alcohol poisoning, which was twice the expected number of deaths. The peculiarity of suicides is that the increase in their number begins two months before the birthday, with a maximum at 35 days, followed by a decrease and a sharp increase on the birthday. Further suicide mortality is cyclical, with peaks at 7 and 15 days after the birthday. Comparison with other holidays showed that birthdays, in terms of excess mortality, occupy an intermediate position between the New Year and other public holidays. The main factor in excess mortality on holidays is the abuse of strong alcoholic beverages.

Conclusion. Birthday celebrations, like public holidays, are accompanied by an increase in mortality. Furthermore, it is easy to assume that the loss is not limited to mortality: there are many more people who fall ill on their birthday than those who die on the occasion.

Key words: birthday, excess mortality, diseases of the circulatory system, external causes, alcohol poisoning, suicide, homicides.

AleXANDer Nemtsov (nemtsov33@gmail.com), NATIONAL SCIENTIFIC CENTER FOR NARCOlOGy, MiniSTRY OF HEALTH OF THE RUSSIAN FEDERATION, RUSSIA.

Timur FATtakHov (timur300385@mail.ru), NATIONAL RESEARCh University Higher SCHOOL OF ECONOMics, RUSSIA.

THE ARTICLE PARTIALLY USED THE RESULTS OBTAINED IN THE FRAMEWORK OF THE PROGRAM OF FUNDAMENTAL RESEARCH OF THE NATIONAL RESEARCH UNIVERSITY HighER SCHOOL OF ECONOMICS.

DATE RECEIVED : SEPTEMBER 2021. 


\section{REFERENCES}

Abel E., Kruger M. (2009). Mortality Salience of Birthdays on Day of Death in the Major Leagues". Death Studies, 33 (2), 175-184. DOI:10.1080/07481180802138936 .

Ajdacic-Gross V., Knopfli D., Landolt K. et al. (2012). Death has a preference for birthdays - an analysis of death time series. Annals of Epidemiology, 22(8), 603-606.

DOI:10.1016/j.annepidem.2012.04.016

Anderson M. (1975). Relationship between month of birth and month of death in the elderly. British Journal of Preventive \& Social Medicine, 29(3), 151-156. DOI:10.1136/jech.29.3.151 .

Bovet J., Spagnoli J., Sudan C. (1997). Mortalité et anniversaire de naissance. (In French; Mortality and birthday. Soz Präventivmed, 42(3), 155-161. DOI:10.1007/BF01300566

Cleveland W., Devlin S. (1988). Locally-Weighted Regression: An Approach to Regression Analysis by Local Fitting. Journal of the American Statistical Association, 83, 596-610. http://dx.doi.org/10.2307/2289282

Corrao G., Rubbiati L., Bagnardi V., Zambon A., Poikolainen K. (2000). Alcohol and coronary heart disease: a meta-analysis. Addiction, 95(10),1505-1523. DOI:10.1046/j.13600443.2000.951015056.x.

Deisenhammer E.A., Stiglbauer C., Kemmler G. Zeitliche (2018). Aspekte von Suiziden Häufigkeit von Suiziden in Beziehung zu Geburtstag, Feiertagen, Wochentagen, Jahreszeit sowie Geburtsmonat und Sternzeichen (In German: Time-related aspects of suicides - suicide frequency related to birthday, major holidays, day of the week, season, month of birth and zodiac signs. Neuropsychiatr, 32(2), 93-100. DOI:10.1007/s40211-018-0260-7

Doblhammer G. (1999). Longevity and month of birth: Evidence from Austria and Denmark. Demographic Research, 1(3), 1-22. DOI:10.4054/DemRes.1999.1.3 .

Handysides S. (2011). Characteristics of patients who consult their GP on their birthdays. $\mathrm{Br} J$ Gen Pract., 61(590), 575-576. DOI:10.3399/bjgp11X593974.

Lopakov K.V. (2011). Otsenka dostovernosti kodirovaniya prichin smerti (po materialam pilotnogo issledovaniya) [Evaluation of the reliability of the coding of causes of death (based on the materials of the pilot study]. Sotsial'nyye aspekty zdorov'ya naseleniya, 2. (In Russ.).

Matsubayashi T., Lee Mj., Ueda M. (2019). Higher Risk of Suicide on Milestone Birthdays: Evidence from Japan. Sci Rep 9, 16642. DOI:10.1038/s41598-019-53203-4

Medenwald D., Kuss O. (2014). Deaths and major biographical events: a study of all cancer deaths in Germany from 1995 to 2009. BMJ Open, 4(4): e004423. DOI:10.1136/bmjopen2013-004423

Motohashi Y. (2012). Suicide in Japan. The Lancet, 9823, 1282-1283. DOI:10.1016/S01406736(11)61130-6

Mukherjee S., Kumar U. (2017). Theorizing Suicide: Multiple Perspectives and Implications for Prevention. In Kumar U. (Ed.), Handbook of suicidal behaviour. Bangalore: Springer Nature (Chapter 1, pp. 3-22).

Nemtsov A.V., Fattakhov T.A. (v pechati). Diagnosticheskiy i vozrastnoy sostav izbytochnoy smertnosti v svyazi s yanvarskimi prazdnikami v Rossii [Diagnostic and age composition of excess mortality in connection with the January holidays in Russia]. Naseleniye $i$ ekonomika. (In Russ.). 
Nemtsov A.V., Simonov A.N., Fattakhov T.A., Gridin R.V. (2021). Izbytochnaya smertnost' v Rossii v prazdnichnyye dni [Excess mortality in Russia on holidays]. Demograficheskoye obozreniye, 8(1), 16-43. DOI:10.17323/demreview.v8i1.12392 (In Russ.).

Peña P. (2015). A not so happy day after all: Excess death rates on birthdays in the U.S. Social Science \& Medicine, 126, 59-66. DOI:10.1016/j.socscimed.2014.12.014 .

Phillips D., Van Voorhees C., Todd R. (1992). The Birthday: Lifeline or Deadline? Psychosomatic Medicine, 54 (5), 532-542. DOI:10.1097/00006842-19920900000001

Pridemore W.A. (2002). Vodka and violence: alcohol consumption and homicide rates in Russia. American Journal of Public Health. 92(12), 1921-1930. DOI:10.2105/AJPH.92.12.1921

Radkevich L.A., Kabankin A.S., Radkevich D.A. (2017). Smertnost' ot suitsida i alkogolizma, zavisimaya ot urovnya potrebleniya alkogol'nykh napitkov [Mortality from suicide and alcoholism, depending on the level of consumption of alcoholic beverages]. Research'n Practical Medicine Journal, 4(1), 33-39. DOI:10.17709/2409-2231-2017-4-1-4 (In Russ.).

Razvodovskiy YU.E. (2006). Alkogol' i serdechno-sosudistaya smertnost' v Belarusi [Alcohol and cardiovascular mortality in Belarus]. Zhurnal GRGMU, 4, 37-42. (In Russ.).

Reulbach U., Biermann T., Markovic K., Bleich S. (2007). The myth of the birthday blues: a population-based study about the association between birthday and suicide. Comprehensive Psychiatry, 48, 554-557. DOI:10.1016/j.comppsych.2007.06.006

Semenova V.G., Gavrilova N.S., Yevdokushkina G.N., Gavrilov L.A. (2004). Kachestvo mediko-statisticheskikh dannykh kak problema sovremennogo rossiyskogo zdravookhraneniya [The quality of medical and statistical data as a problem of modern Russian health care]. Obshchestvennoye zdorov'ye i profilaktika zabolevaniy, 2, 11-19. (In Russ.).

Simou E., Britton J., Leonardi-Bee J. (2018). Alcohol and the risk of pneumonia: a systematic review and meta-analysis, BMJ Open, 8(8): e022344. DOI:10.1136/bmjopen-2018-022344

Stickley A., Sheng Ng.C., Inoue Y., Yazawa A., Koyanagi A., Kodaka M., DeVylder J., Watanabe Ch. (2016). Birthdays are associated with an increased risk of suicide in Japan: Evidence from 27,007 deaths in Tokyo in 2001-2010. Journal of Affective Disorders, 200, 259-265. DOI:10.1016/j.jad.2016.04.028

Vaiserman A., Grigoryev P., Belaya I., Voitenko V. (2003). Variation of mortality rate during the individual annual cycle. Biogerontol, 4(4), 221-225. DOI:10.1023/A:1025168932058.

WHO (2006). Mezhlichnostnoye nasiliye i alkogol' v Rossiyskoy Federatsii. Vsemirnaya organizatsiya zdravookhraneniya. Yevropeyskoye regional'noye byuro [Interpersonal violence and alcohol in the Russian Federation]. https://apps. who.int/iris/bitstream/handle/10665/107355/e88757r.pdf;jsessionid=9A8A33451 C7C2F78D16AA55218F945AA?sequence=2 (In Russ.).

Williams A., While D., Windfuhr K., Bickley H., Hunt I.M., Shaw J., Appleby L., Kapur N. (2011). Birthday Blues, Examining the Association Between Birthday and Suicide in a National Sample. Crisis, 32, 134-142. DOI:10.1027/0227-5910/a000067 